Check for updates

Cite this: Phys. Chem. Chem. Phys., $2018,20,28267$

Received 8th August 2018, Accepted 28th October 2018

DOI: $10.1039 / c 8 c p 05061 a$

rsc.li/pccp

\section{Effect of the degree of inversion on optical properties of spinel $\mathrm{ZnFe}_{2} \mathrm{O}_{4}^{\dagger}$}

\author{
Luis I. Granone, (D)*ab Anna C. Ulpe, (D) ${ }^{c}$ Lars Robben, (D) de Stephen Klimke, ${ }^{f}$ \\ Moritz Jahns, ${ }^{f}$ Franz Renz, ${ }^{f}$ Thorsten M. Gesing, (iD de Thomas Bredow, ${ }^{C}$ \\ Ralf Dillert (iD *ab and Detlef W. Bahnemann (iD) abg
}

\begin{abstract}
Spinel ferrites $\left({ }^{\top}\left[\mathrm{M}_{1-x} \mathrm{Fe}_{x}\right]^{\mathrm{C}}\left[\mathrm{M}_{x} \mathrm{Fe}_{2-x}\right] \mathrm{O}_{4}\right.$ with $0 \leq x \leq 1$, where $M$ is a bivalent metal ion and the superscripts denote tetrahedral and octahedral sites) are materials commonly used in electronics due to their outstanding magnetic properties. Thus, the effect of the degree of inversion, $x$, on these properties is well known. However, its effect on other properties of these materials has rarely been investigated in detail. Since ferrites gained much attention during the last decade as visible light active photocatalysts and photoelectrocatalysts, understanding the effect of the degree of inversion on the optical properties became necessary. Among photocatalytically and photoelectrocatalytically active spinel ferrites, zinc ferrite $\left(\mathrm{ZnFe}_{2} \mathrm{O}_{4}, \mathrm{ZFO}\right)$ is one of the most widely studied materials. In this work, five ZFO samples with degrees of inversion varying from 0.07 to 0.20 were prepared by a solid-state reaction employing different annealing temperatures and subsequent quenching. Raman and UV-Vis-NIR spectra were measured and analyzed together with theoretical results obtained from ab initio calculations. Changes in the UV-Vis-NIR spectra associated with electronic transitions of tetrahedrally and octahedrally coordinated $\mathrm{Fe}^{3+}$ ions are distinguished. However, the optical band gap of the material remains unchanged as the degree of inversion varies. Based on the experimental and theoretical results, a new assignment for the Raman active internal modes and the electronic transitions of ZFO is proposed.
\end{abstract}

\section{Introduction}

Spinel ferrites are versatile materials with several applications in the fields of information storage, ${ }^{1}$ magnetic fluids, ${ }^{2}$ microwave devices, ${ }^{3}$ and catalysis. ${ }^{4}$ Undoubtedly, their outstanding magnetic properties make spinel ferrites such interesting materials for these purposes. ${ }^{5}$ However, other properties, such as semiconductivity, are nowadays scientifically explored.

\footnotetext{
${ }^{a}$ Institute of Technical Chemistry, Gottfried Wilhelm Leibniz University Hannover, Callinstrasse 3, D-30167 Hannover, Germany.

E-mail: granone@iftc.uni-hannover.de, dillert@iftc.uni-hannover.de

${ }^{b}$ Laboratory of Nano- and Quantum-Engineering (LNQE), Gottfried Wilhelm Leibniz University Hannover, Schneiderberg 39, D-30167 Hannover, Germany

${ }^{c}$ Universität Bonn, Mulliken Center for Theoretical Chemistry, Institut für Physikalische und Theoretische Chemie, Beringstrasse 4, D-53115 Bonn, Germany

${ }^{d}$ University of Bremen, Institute of Inorganic Chemistry and Crystallography, Leobener Strasse 7, D-28359 Bremen, Germany

${ }^{e}$ University of Bremen, MAPEX Center for Materials and Processes, Bibliothekstrasse 1, D-28359 Bremen, Germany

${ }^{f}$ Institute for Inorganic Chemistry, Gottfried Wilhelm Leibniz University Hannover, Callinstrasse 9, D-30167 Hannover, Germany

${ }^{g}$ Laboratory "Photoactive Nanocomposite Materials", Saint-Petersburg State University, Ulyanovskaya Str. 1, 198504 Peterhof, Saint-Petersburg, Russian Federation

$\dagger$ Electronic supplementary information (ESI) available. See DOI: 10.1039/c8cp05061a
}

Recently, semiconducting spinel ferrites $\left(\mathrm{MFe}_{2} \mathrm{O}_{4}, \mathrm{M}=\right.$ metal ion) have attracted attention in the fields of photocatalysis and photoelectrocatalysis. ${ }^{6,7}$ Applications of spinel ferrites in these research areas include artificial photosynthesis, ${ }^{7}$ carbon dioxide conversion, ${ }^{8}$ hydrogen and oxygen generation via water splitting, ${ }^{9-11}$ and water treatment. ${ }^{12}$ Properties such as narrow band gaps $(\approx 2 \mathrm{eV})$, high chemical stability, abundance, and low cost make spinel ferrites promising materials for the applications mentioned above. ${ }^{6,7}$

$\mathrm{MFe}_{2} \mathrm{O}_{4}$ crystallizes in a face-centered cubic structure like the mineral spinel $\left(\mathrm{MgAl}_{2} \mathrm{O}_{4}\right)$, after which this class of materials is named. In the so-called normal structure, $\mathrm{M}^{2+}$ and $\mathrm{Fe}^{3+}$ ions occupy $1 / 8$ of the tetrahedral sites and $1 / 2$ of the octahedral sites available in the $\mathrm{O}^{2-}$ lattice, respectively. However, when all the $\mathrm{M}^{2+}$ ions at the tetrahedral sites are exchanged by $\mathrm{Fe}^{3+}$ ions from the octahedral sites, the material adopts a so-called inverse structure. The parameter commonly employed to characterize the cation disorder is the degree of inversion, $x$, defined as the fraction of $\mathrm{M}^{2+}$ ions occupying octahedral sites, according to ${ }^{\mathrm{T}}\left[\mathrm{M}_{1-x} \mathrm{Fe}_{x}\right]^{\mathrm{O}}\left[\mathrm{M}_{x} \mathrm{Fe}_{2-x}\right] \mathrm{O}_{4}$.

Among photocatalytically and photoelectrocatalytically active spinel ferrites, zinc ferrite $\left(\mathrm{ZnFe}_{2} \mathrm{O}_{4}, \mathrm{ZFO}\right)$ is one of the most widely studied materials. ${ }^{13,14}$ At standard conditions $(273.15 \mathrm{~K}$ and $100 \mathrm{kPa}$ ), the normal structure is the thermodynamically 
most stable configuration for bulk ZFO. ${ }^{15}$ Nevertheless, it is known that ZFO does not usually exhibit a normal structure and the degree of inversion closely depends on the synthetic conditions. $^{15-20}$ This effect is especially pronounced when nanoparticulate ZFO samples are synthesized. Akhtar et al. ${ }^{18}$ reported the sol-gel synthesis of ZFO nanoparticles having degrees of inversion of 0.5 or 0.25 when urea or citric acid, respectively, are used as precursors. Kamiyama et al. ${ }^{19}$ reported the co-precipitation synthesis of ZFO nanoparticles with a degree of inversion of 0.142 and Nakashima et al. ${ }^{20}$ prepared nanoparticulate ZFO with a degree of inversion of 0.6 by radiofrequency sputtering. ZFO nanoparticles having a high degree of inversion have been prepared by Kurian and Mathew ${ }^{21}$ using a solvothermal technique. They reported a degree of inversion of $0.54 .^{21}$ Šepelák et al. ${ }^{22}$ investigated the effect of high-energy ball-milling in the cation distribution of nanoscaled ZFO. The authors showed an increase in the degree of inversion from 0 to 0.94 , i.e., from normal spinel to almost completely inversed spinel by increasing the milling time.

Mozaffari et $a .^{23}$ and Yuan et $a .^{24}$ reported that the magnetization of ZFO increases as the degree of inversion becomes larger. Harris et $a l^{25}$ reviewed the effect of the degree of inversion of mechanochemically processed ZFO nanoparticles not only on the magnetization but also on the Néel temperature and the nuclear magnetic properties, including hyperfine field distributions, isomer shifts, and quadrupole interactions. ZFO samples prepared by mechanochemical methods show degrees of inversion close to $2 / 3 .^{25}$ As a consequence, a ferrimagnetic behavior is observed at room temperature for the highly disordered ZFO samples. Conversely, an antiferromagnetic behavior with a Néel temperature of $10.5 \mathrm{~K}$ is observed for normal $\mathrm{ZFO} .^{25}$

Although the effect of the degree of inversion on the magnetic properties is well known, some other physicochemical properties have not been until now investigated in detail. Among these, the optical properties are of utmost importance for the characterization of a material with applications in optoelectronics, photocatalysis, and photoelectrocatalysis. On the one hand, the UV and visible light absorptivity of a material is directly related with the maximum photonic efficiency that can be expected under defined experimental conditions. On the other hand, Raman spectroscopy is a commonly employed technique for the characterization of ZFO. Wang et al. ${ }^{26}$ reported a first order Raman spectrum of a ZFO sample having a degree of inversion of 0.10 . The authors correlated the observed signals with the five Raman active internal modes predicted by the factor group analysis. ${ }^{26}$ The experimental data presented in the current study demonstrate that some of the signals detected by Wang et al. are originated due to a symmetry perturbation because of the cation disordering and, thus, are not active internal modes. Regarding the absorptivity of ZFO, Pailhé et al. ${ }^{27}$ reported a diffuse reflectance Vis-NIR spectrum of a sample with a degree of inversion of 0.140 . For the interpretation of some of the electronic transitions, the authors considered the splitting of the $\mathrm{Fe}(3 \mathrm{~d})$ orbitals on the basis of the RussellSaunders coupling. ${ }^{27}$ However, they also assigned some transitions on the basis of a simple splitting of the $\mathrm{Fe}\left(3 \mathrm{~d}\right.$ ) orbitals (into $\mathrm{t}_{2 \mathrm{~g}}$ and $e_{g}$ orbitals), thus presenting ambiguous results.
To the best of our knowledge, the effect of the degree of inversion on the Raman scattering and UV-Vis-NIR absorptivity of ZFO has not been studied in detail before. For the first time, Raman spectra of normal and inverted ZFO were calculated, obtaining an excellent agreement with the experimental results. The combination of $a b$ initio calculations and experimental data allowed to describe how the optical properties of ZFO evolve as the degree of inversion increases from $x \approx 0.07$ to $x \approx 0.20$. Furthermore, fundamental properties such as the assignment of the Raman active internal modes and the electronic transitions were analyzed. The experimental and theoretical evidence presented in this work supports a new interpretation for both, the Raman active internal modes and the electronic transitions of spinel ZFO.

\section{Materials and methods}

Polycrystalline ZFO samples were synthesized by means of a solid-state reaction. Stoichiometric amounts of $\mathrm{ZnO}$ (Sigma Aldrich, $\geq 99.0 \%$ ) and $\mathrm{Fe}_{2} \mathrm{O}_{3}$ (Sigma Aldrich, $\geq 99.0 \%$ ) powders were mixed together using an agate mortar. The mixture was calcined in air at $1073 \mathrm{~K}$ with a heating rate of $350 \mathrm{~K} \mathrm{~h}^{-1}$. After 12 hours, the sample was cooled to room temperature and grinded again in an agate mortar. Aliquots of $0.500 \mathrm{~g}$ were pressed into $13 \mathrm{~mm}$ diameter pellets applying a pressure of $55 \mathrm{MPa}$. The pellets were calcined at $1273 \mathrm{~K}$ with a heating rate of $150 \mathrm{~K} \mathrm{~h}^{-1}$. After 2 hours at this temperature, the samples were cooled to $1073 \mathrm{~K}$ with a cooling rate of $100 \mathrm{~K} \mathrm{~h}^{-1}$, then kept at $1073 \mathrm{~K}$ for 12 hours, cooled to $773 \mathrm{~K}$ at a rate of $100 \mathrm{~K} \mathrm{~h}^{-1}$, kept at $773 \mathrm{~K}$ for 50 hours, and finally quenched in cold water. Some of the pellets (referred from now as ZFO_773) were retained for further characterization. The rest were divided into four sets of samples. The samples were heated up with a rate of $300 \mathrm{~K} \mathrm{~h}^{-1}$ and calcined at 873, 973, 1073, and $1173 \mathrm{~K}$ for $25,20,12$, and 10 hours, respectively. After this period of time, the calcined pellets were immediately quenched in cold water. These samples will be referred as ZFO_873, ZFO_973, ZFO_1073, and ZFO_1173.

Powder X-ray diffraction data were collected with an StadiMP diffractometer (Stoe \& Cie., Darmstadt, Germany) using monochromatized $\mathrm{MoK} \alpha_{1}$ radiation $(\lambda=70.9300 \mathrm{pm})$ and a Mythen2 $1 \mathrm{~K}$ detector (Dectris, Baden-Daettwil, Switzerland). Flat samples for transmission measurements were prepared by placing the sample between two thin mylar foils and fixing these with a metal ring providing a $3 \mathrm{~mm}$ hole. The diffraction pattern were recorded in transmission geometry in the $2 \theta$ range from $2^{\circ}$ to $92^{\circ}$, collecting 5977 data points with a step width of $0.015^{\circ} 2 \theta$ and $270 \mathrm{~s}$ measurement time per step. Rietveld refinements were carried out using the Bruker DIFFRAC ${ }^{\text {plus }}$ TOPAS V4.2 software (Bruker AXS Inc., Madison, Wisconsin, USA). The space group $F d \overline{3} m$, with the zinc and iron ions placed in tetrahedral and octahedral sites, respectively, was assumed as starting point for the refinement. The scale factors, lattice parameters, oxygen positional parameters, inversion parameters, the three isotropic displacement parameters, and the zero point were optimized 
during the refinements. The standard instrumental parameters were determined with $\mathrm{LaB}_{6}$ standard (SRM 660c, NIST).

Mössbauer measurements were performed in transmission mode using a Miniaturized Mössbauer Spectrometer MIMOS II with the sample perpendicular to the ${ }^{57} \mathrm{Co} / \mathrm{Rh}$ source. The samples were placed into a spherical sample holder and the cap was subsequently rotated to align the crystals in the $x y$-plane. All isomer shifts are given relative to $\alpha$-Fe at room temperature. The data were fitted by least-squares method using Lorentzian line shapes with the Recoil 1.05 Mössbauer Analysis software. ${ }^{28}$

Raman measurements were made employing a confocal Bruker Senterra micro-Raman spectrometer. Depolarized spectra were collected at ambient conditions in backscattering geometry using an Olympus BX 51 microscope that allows the incident $785 \mathrm{~nm}, 633 \mathrm{~nm}$, or $532 \mathrm{~nm}$ laser beam to be focused on the sample as a spot of about $2 \mu \mathrm{m}$ in diameter. An integration time of $5 \mathrm{~s}, 20$ co-additions, and a power of $50 \mathrm{~mW}, 2 \mathrm{~mW}$, and $2 \mathrm{~mW}$ for the $785 \mathrm{~nm}, 633 \mathrm{~nm}$, and $532 \mathrm{~nm}$ lasers, respectively, were used. The instrumental precision was within $\pm 3 \mathrm{~cm}^{-1}$.

Raman spectra were calculated using the CRYSTAL14 program package, ${ }^{29}$ employing triple- $\zeta$ basis sets. The frequencies were calculated using the range separated functional HSE06, ${ }^{30}$ while the intensities were calculated with B3LYP. ${ }^{31}$ A well-converged Monkhorst-Pack grid of $8 \times 8 \times 8$ was sufficient. The atomic positions of normal and inverse ZFO were optimized using an experimental lattice parameter of $a=844.32 \mathrm{pm}^{32}$

UV-Vis-NIR spectroscopy was carried out with an Agilent Carry 5000 device equipped with an external DRA-2500 Diffuse Reflectance Accessory. The spectra were collected in the range of $200 \mathrm{~nm}$ to $2000 \mathrm{~nm}$ with a data acquisition interval of $1 \mathrm{~nm}$, an averaging time of $0.1 \mathrm{~s}$, a scan rate of $600 \mathrm{~nm} \mathrm{~min}{ }^{-1}$, and a spectral bandwidth of $2 \mathrm{~nm}$. The instrumental precision was within $\pm 0.5 \mathrm{~nm}$. The optical band gaps were determined by the derivation of absorption spectrum fitting method (DASF). ${ }^{33}$

Optical spectra of normal and inverse ZFO were calculated using the Vienna $a b$ initio Simulation Package (VASP) ${ }^{34}$ version 5.4.4. A carefully converged quasi-particle $\mathrm{GW} 0^{35}$ algorithm was employed and to gain insight about the optical properties, the Bethe-Salpeter-Equations (BSE) ${ }^{36}$ were solved afterwards. For normal ZFO, an experimental structure ${ }^{32}$ was used, while for inverse ZFO, an optimization of atomic positions was performed.

The composition of the samples was determined analytically by means of inductively coupled plasma optical emission spectrometry (ICP-OES) using a Spectroflame and Spectro Arcos from Spectro Analytical Instruments. Fe and $\mathrm{Zn}$ were quantified by measuring the optical emission at $259.941 \mathrm{~nm}$ and $213.856 \mathrm{~nm}$, respectively, and comparing with the calibration curve prepared using the respective ICP standards (Carl Roth). Prior to the analysis, the samples were dissolved in freshly distilled 16\% HCl (Carl Roth) at $473 \mathrm{~K}$ using an ultraWAVE microwave digestion system from MLS GmbH.

The structural and morphological properties of the samples were analyzed using a JEOL JSM-6700F scanning electron microscope provided with a lower secondary electron image detector. An acceleration voltage of $2.0 \mathrm{kV}$ and a 25000 times magnification were employed.

\section{Results and discussions}

ZFO samples with degree of inversion of approximately 0.07 , $0.10,0.13,0.16$, and 0.20 were synthesized by means of a solidstate reaction. An initial calcination at $1273 \mathrm{~K}$ was carried out for all the samples in order to ensure the homogeneity of the crystallinity and the crystallite size between them. The degree of inversion was modified by further calcination steps at temperatures ranging from $773 \mathrm{~K}$ to $1173 \mathrm{~K}$ and subsequent quenching of the samples in cold water. The samples were characterized employing XRD and Rietveld refinement (Fig. S1, ESI $\dagger$ ), Mössbauer spectroscopy (Table S1 and Fig. S2, ESI $\dagger$ ), Raman spectroscopy (Fig. 2 and Fig. S5, ESI $\dagger$ ), and elemental analysis. The elemental analysis revealed a $\mathrm{Fe}$ to $\mathrm{Zn}$ ratio close, within the experimental error, to $2: 1$ as expected for ZFO. This ratio will also hold in the case that a mixture of equal amounts of $\mathrm{Fe}_{2} \mathrm{O}_{3}$ and $\mathrm{ZnO}$ is present. However, XDR (Fig. S1, ESI $\dagger$ ) and Raman (Fig. 2) data give no indication of the presence of $\mathrm{ZnO}$ or hematite $\left(\alpha-\mathrm{Fe}_{2} \mathrm{O}_{3}\right)$. Maghemite $\left(\gamma-\mathrm{Fe}_{2} \mathrm{O}_{3}\right)$, having a spinel structure, might not be distinguished from ZFO in an XRD diffractogram. However, the presence of $\gamma-\mathrm{Fe}_{2} \mathrm{O}_{3}$ is excluded based on the Raman (Fig. S6, ESI $\dagger$ ) and Mössbauer data (Fig. S3, ESI $\dagger$ ). The strongest Raman scattering signal of $\gamma-\mathrm{Fe}_{2} \mathrm{O}_{3}$, located at $670 \mathrm{~cm}^{-1}$, might not be differentiated from the broad ZFO band at ca. $647 \mathrm{~cm}^{-1} \cdot{ }^{37}$ However, the next strongest and characteristic band of $\gamma-\mathrm{Fe}_{2} \mathrm{O}_{3}$, located at $718 \mathrm{~cm}^{-1}, 37$ is not observed in the Raman spectra of ZFO (Fig. S6, ESI $\dagger$ ). A more conclusive evidence of the absence of $\gamma-\mathrm{Fe}_{2} \mathrm{O}_{3}$ comes from the Mössbauer data. A sextet is observed in the Mössbauer spectrum of $\gamma-\mathrm{Fe}_{2} \mathrm{O}_{3}$ (Fig. S3, ESI $\dagger$ ) due to its room temperature ferrimagnetism. ${ }^{37}$ However, only two duplets (due to the $\mathrm{Fe}^{3+}$ cations present in tetrahedral and octahedral sites) are observed in the Mössbauer spectra of the ZFO samples (Fig. S2, ESI $\dagger$ ). This is because of the room temperature paramagnetism of the ZFO samples. Therefore, the presence of $\gamma-\mathrm{Fe}_{2} \mathrm{O}_{3}$ as secondary phase in the ZFO samples is excluded.

The values deduced from Rietveld refinement and Mössbauer spectroscopy together with the structural parameters and the iron to zinc molar ratios obtained from the elemental analysis of the different quenched ZFO samples are given in Table 1. Neither secondary phases nor impurities could be detected from the XRD patterns. Furthermore, none of the samples showed Mössbauer signals attributable to $\mathrm{Fe}^{2+}$. Hence, the absence of $\mathrm{Fe}^{2+}$ and, therefore, of oxygen vacancies has been confirmed by Mössbauer spectroscopy.

As becomes obvious from Fig. 1A, the degree of inversion increases linearly with the calcination temperature from $0.074 \pm 0.011$ at $773 \mathrm{~K}$ to $0.203 \pm 0.017$ at $1173 \mathrm{~K}$. A similar behavior was reported by O'Neill ${ }^{15}$ using powder XRD structure refinements, and by Pavese et al. ${ }^{16}$ from in situ high-temperature neutron powder diffraction data evaluation (Fig. 1B). The results from O'Neill show a monotonic increase in the degree of inversion from 0.019 at $773 \mathrm{~K}$ to 0.149 at $1073 \mathrm{~K}$, and then a plateau. The author suggested that this plateau results from the re-ordering kinetics at temperatures higher than $1173 \mathrm{~K}$ being too fast to allow a quenching of the sample. ${ }^{16}$ This effect was 
Table 1 Refined structural parameters, degree of inversion deduced from Mössbauer spectroscopy, and Fe to $\mathrm{Zn}$ molar ratios of the different temperature annealed ZFO samples. $n_{\mathrm{Fe}} / n_{\mathrm{Zn}}$ is the Fe to $\mathrm{Zn}$ molar ratio, $x$ is the degree of inversion, $a$ is the lattice parameter, $x(O)$ is the oxygen positional parameter on 32e: $x, x, x$ in $F d \overline{3} m, L_{\mathrm{Vol}}(\mathrm{IB})$ is the average crystallite size, and $B_{\mathrm{Zn}}, B_{\mathrm{Fe}}$, and $B_{\mathrm{o}}$ are the isotropic displacement parameters concerning the $\mathrm{Zn}^{2+}, \mathrm{Fe}^{3+}$, and $\mathrm{O}^{2-}$ ions, respectively

\begin{tabular}{|c|c|c|c|c|c|c|c|c|c|c|}
\hline \multirow[b]{2}{*}{$\begin{array}{l}\text { Calcination } \\
\text { temperature/K }\end{array}$} & \multirow[b]{2}{*}{$n_{\mathrm{Fe}} / n_{\mathrm{Zn}}$} & \multicolumn{3}{|c|}{ Degree of inversion $x$} & \multirow[b]{2}{*}{$a / \mathrm{pm}$} & \multirow[b]{2}{*}{$x(\mathrm{O})$} & \multirow[b]{2}{*}{$L_{\mathrm{Vol}}(\mathrm{IB}) / \mathrm{nm}$} & \multirow[b]{2}{*}{$B_{\mathrm{Zn}} / \AA^{2}$} & \multirow[b]{2}{*}{$B_{\mathrm{Fe}} / \AA^{2}$} & \multirow[b]{2}{*}{$B_{\mathrm{o}} / \AA^{2}$} \\
\hline & & $\begin{array}{l}\text { Rietveld } \\
\text { refinement (RR) }\end{array}$ & $\begin{array}{l}\text { Mössbauer } \\
\text { spectroscopy (MS) }\end{array}$ & $\left(\frac{x_{\mathrm{RR}}+x_{\mathrm{MS}}}{2}\right)$ & & & & & & \\
\hline 773 & $1.98 \pm 0.04$ & $0.073(7)$ & $0.074 \pm 0.015$ & $0.074 \pm 0.011$ & $844.285(5)$ & $0.26025(13)$ & $306(6)$ & $0.38(1)$ & $0.37(1)$ & $0.39(3)$ \\
\hline 873 & $1.98 \pm 0.05$ & $0.106(6)$ & $0.102 \pm 0.020$ & $0.104 \pm 0.013$ & $844.433(5)$ & $0.26001(11)$ & $293(5)$ & $0.48(1)$ & $0.37(1)$ & $0.50(2)$ \\
\hline 973 & $1.97 \pm 0.04$ & $0.131(6)$ & $0.136 \pm 0.010$ & $0.134 \pm 0.008$ & $844.374(5)$ & $0.26001(11)$ & $302(5)$ & $0.53(1)$ & $0.52(1)$ & $0.56(2)$ \\
\hline 1073 & $1.98 \pm 0.03$ & $0.161(7)$ & $0.156 \pm 0.012$ & $0.159 \pm 0.010$ & $844.432(5)$ & $0.25996(12)$ & $327(6)$ & $0.50(1)$ & $0.53(1)$ & $0.53(2)$ \\
\hline 1173 & $1.98 \pm 0.07$ & $0.196(7)$ & $0.210 \pm 0.028$ & $0.203 \pm 0.017$ & $844.427(5)$ & $0.25954(13)$ & $283(6)$ & $0.34(1)$ & $0.36(1)$ & $0.41(3)$ \\
\hline
\end{tabular}
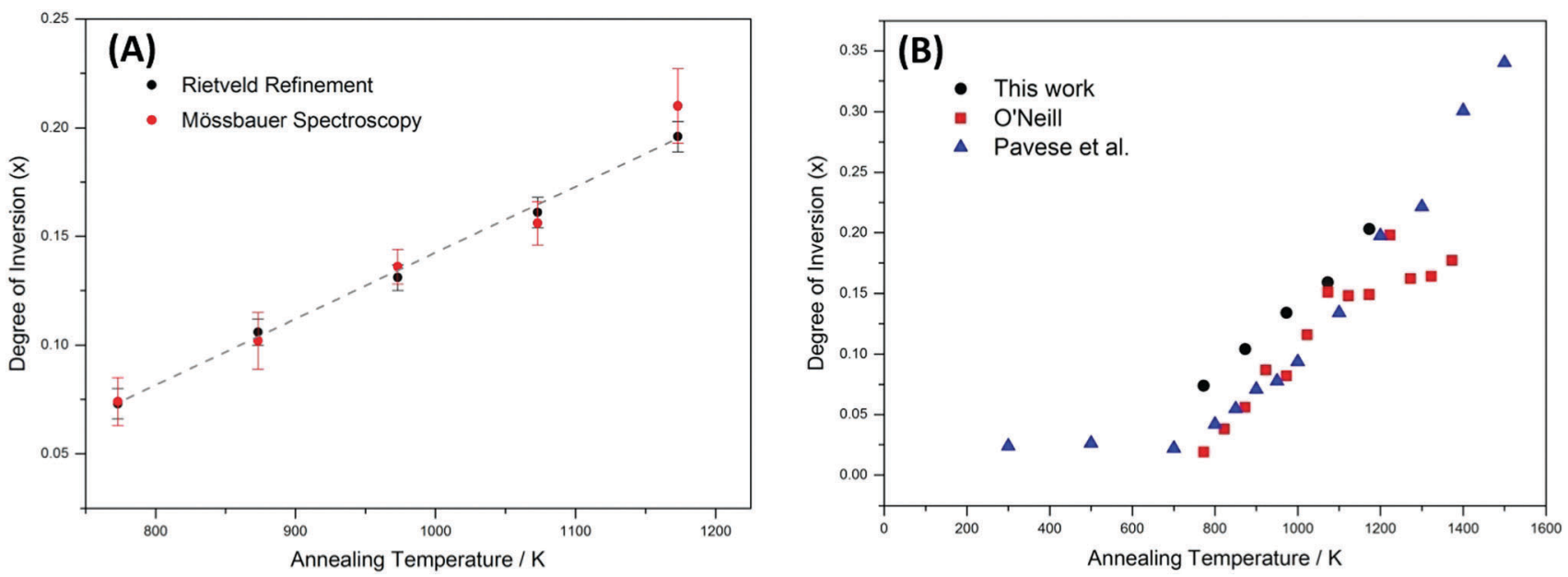

Fig. 1 (A) Degree of inversion, $x$, versus the annealing temperature. (B) Comparison of the present result with values obtained by $\mathrm{O}^{\prime} \mathrm{Neill}{ }^{15}$ and Pavese et al. ${ }^{16}$

not observed by Pavese et al. because their measurements were done in situ..$^{16}$

A comprehensible work regarding the thermodynamics of the cation disorder and the dependence of the degree of inversion with the temperature have been done by Callen et al., ${ }^{38}$ Navrotsky and Kleppa, ${ }^{39}$ O'Neill and Navrotsky, ${ }^{40,41}$ and O'Neill. ${ }^{15}$ The cation distribution in ZFO can be treated as a dynamic equilibrium according to the following interchange reaction between ions being present in tetrahedral (subscript "T") and octahedral sites (subscript “O”):

$$
{ }^{\mathrm{T}} \mathrm{Zn}+{ }^{\mathrm{O}} \mathrm{Fe} \rightleftarrows{ }^{\mathrm{O}} \mathrm{Zn}+{ }^{\mathrm{T}} \mathrm{Fe}
$$

A summary reviewing the thermodynamic analysis of the temperature effect on the degree of inversion is presented in the ESI $\dagger$ (Fig. S4).

The Raman spectra of the different ZFO samples are shown in Fig. 2. In agreement with the XRD data, no signals attributed to impurities or secondary phases are identified. The ZFO sample with the lowest degree of inversion (ZFO_773, $x=0.074 \pm 0.011$ ) shows five bands at $176.5 \pm 3 \mathrm{~cm}^{-1}, 251 \pm 3 \mathrm{~cm}^{-1}$ (weak), $352 \pm 3 \mathrm{~cm}^{-1}, 447 \pm 3 \mathrm{~cm}^{-1}$, and $647 \pm 3 \mathrm{~cm}^{-1}$ and one minor signal at $155 \pm 3 \mathrm{~cm}^{-1}$. The sharp signal at $352 \pm 3 \mathrm{~cm}^{-1}$ exhibits a broad shoulder at smaller wavenumbers while the band at $447 \pm 3 \mathrm{~cm}^{-1}$ presents a broad shoulder at higher wavenumbers.
The broad signal at $647 \pm 3 \mathrm{~cm}^{-1}$ can be deconvoluted into two Gaussian-shape signals at ca. $644 \mathrm{~cm}^{-1}$ and $675 \mathrm{~cm}^{-1}$ (Fig. S7, ESI $\dagger$ ). Comparing with the Raman spectra measured with $532 \mathrm{~nm}$ and $633 \mathrm{~nm}$ laser excitations (Fig. S5, ESI $\dagger$ ), the relative intensities of the bands change markedly. Interestingly, a signal not present in the spectra obtained with $785 \mathrm{~nm}$ laser excitation is observed at $573.5 \pm 3 \mathrm{~cm}^{-1}$ for the samples having a low degree of inversion. This signal decreases rapidly as the degree of inversion of the samples increases. A grouptheoretical analysis of the vibrational spectrum for the spinel structure made by White and DeAngelis ${ }^{42}$ predicted five Raman active internal modes: $\mathrm{A}_{1 \mathrm{~g}}, \mathrm{E}_{\mathrm{g}}$, and three $\mathrm{T}_{2 \mathrm{~g}} \cdot{ }^{42}$ Because normal and inverse spinel crystallize in the same space group, no change is expected in the number of active internal Raman modes. Nevertheless, when the degree of inversion is neither 0 nor $1(0<x<1)$, the symmetry is perturbed and the number of normal modes increases. ${ }^{43}$ The five predicted Raman active internal modes for the normal structure can be attributed to the signals at $176.5 \pm 3 \mathrm{~cm}^{-1}, 352 \pm 3 \mathrm{~cm}^{-1}, 447 \pm 3 \mathrm{~cm}^{-1}, 573.5 \pm$ $3 \mathrm{~cm}^{-1}$, and $647 \pm 3 \mathrm{~cm}^{-1}$. The weak band at $251 \pm 3 \mathrm{~cm}^{-1}$, and the shoulders and broadening observed for most of the signals are direct consequences of the non-zero degree of inversion, as will be discussed below. Even the sample with a degree of inversion close to $0\left(\mathrm{ZFO}_{-} 773, x=0.074 \pm 0.011\right)$ shows all the mentioned deviations. 


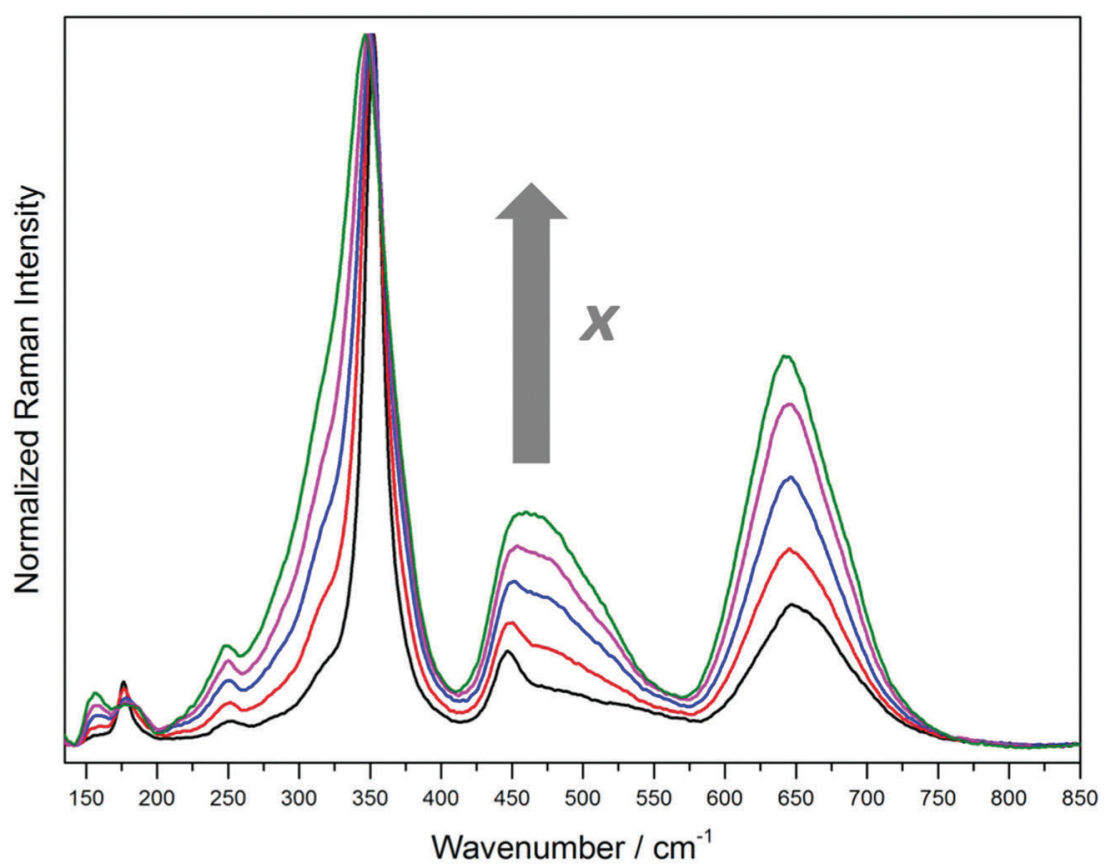

Fig. 2 Normalized Raman spectra of the ZFO samples with increasing degree of inversion ( - ZFO_773, $x=0.074 \pm 0.011 ;-Z F O \_873, x=0.104 \pm 0.013$; -ZFO_973, $x=0.134 \pm 0.008 ;-Z F O \_1073, x=0.159 \pm 0.010 ;-Z F O \_1173, x=0.203 \pm 0.017$ ) obtained using a $785 \mathrm{~nm}$ laser as the excitation source.

Distinctive changes can be observed in the Raman scattering as the degree of inversion of the ZFO samples increases. Fig. 3 shows the magnification of four different regions of the Raman spectra presented above. The first interval, from $141.5 \mathrm{~cm}^{-1}$ to $202 \mathrm{~cm}^{-1}$ (Fig. 3A), exhibits pronounced changes. As the degree of inversion increases, a band almost imperceptible for $x=0.074 \pm 0.011$ becomes higher in intensity at $156 \pm 3 \mathrm{~cm}^{-1}$ and the sharp signal observed at $176.5 \pm 3 \mathrm{~cm}^{-1}$ decreases in intensity. Interestingly, this decrease is accompanied by a growth of a shoulder at higher wavenumbers, resulting in a broad band from $168 \mathrm{~cm}^{-1}$ to $198 \mathrm{~cm}^{-1}$. Supposing that the Raman mode at $176.5 \pm 3 \mathrm{~cm}^{-1}$ is due to vibrations of the $\mathrm{AO}_{4}$ tetrahedral groups, the broadening of this band can be explained by the exchange of $\mathrm{Zn}$ atoms by lighter Fe atoms, resulting in a shift in the vibration frequency to higher wavenumbers.

In the region from $215 \mathrm{~cm}^{-1}$ to $415 \mathrm{~cm}^{-1}$ (Fig. 3B), an increase in the intensity of the weak signal at $251 \pm 3 \mathrm{~cm}^{-1}$ and a broadening of the main band at $352 \pm 3 \mathrm{~cm}^{-1}$ with a small shift of the maximum to smaller wavenumbers are observed as the degree of inversion of the samples increases. The broadening is due to the growth of the shoulder situated at $315 \pm 3 \mathrm{~cm}^{-1}$. This shoulder exhibits a weak intensity for the sample with $x=0.074 \pm 0.011$. Supposing that the signals in this spectral region are predominantly ruled by the vibration of the $\mathrm{AO}_{6}$ octahedral groups, the growth of this shoulder at lower wavenumbers is in concordance with the exchange of Fe atoms by heavier $\mathrm{Zn}$ atoms. Regarding the behavior of the weak signal at $251 \pm 3 \mathrm{~cm}^{-1}$, it can be assumed that it arises due to the perturbation in the symmetry produced by the cation disordering. Hence, this signal is not one of the five predicted Raman active internal modes for the normal structure.
Prominent changes in the Raman spectra are noticed in the interval from $415 \mathrm{~cm}^{-1}$ to $570 \mathrm{~cm}^{-1}$ (Fig. 3C). As the degree of inversion increases, the shoulder of the band observed at $447 \pm 3 \mathrm{~cm}^{-1}$ for the sample with $x=0.074 \pm 0.011$ grows markedly. This finally results in a broad band from $415 \mathrm{~cm}^{-1}$ to $560 \mathrm{~cm}^{-1}$ with a maximum at $460 \pm 3 \mathrm{~cm}^{-1}$ for the sample with $x=0.203 \pm 0.017$. Supposing that the signal at $447 \pm 3 \mathrm{~cm}^{-1}$ arises from the vibrations of the $\mathrm{AO}_{4}$ tetrahedral groups, the increase in the intensity of the shoulder at higher wavenumbers is again a direct consequence of the exchange of $\mathrm{Zn}$ atoms by lighter Fe atoms. As was mentioned above, the Raman active internal mode at $573.5 \pm 3 \mathrm{~cm}^{-1}$ is not intense enough to be detected using a $785 \mathrm{~nm}$ excitation source. Despite this signal is observed in the spectra obtained using $532 \mathrm{~nm}$ and $633 \mathrm{~nm}$ laser excitations, the intensity decreases rapidly as the degree of inversion increases (Fig. S5, ESI $\dagger$ ). This suggests that the vibration of $\mathrm{Zn}$ atoms in the tetrahedral sites is also related to this Raman band. Because the signal decreases in intensity with the increasing degree of inversion, the weak band becomes rapidly imperceptible.

A particular change is observed in the region between $575 \mathrm{~cm}^{-1}$ and $730 \mathrm{~cm}^{-1}$ (Fig. 3D). As the degree of inversion increases from $0.074 \pm 0.011$ to $0.203 \pm 0.017$, the intensity of the broad band at $647 \pm 3 \mathrm{~cm}^{-1}$ grows markedly. The increase in the relative intensity of this band in comparison to the main signal at $352 \pm 3 \mathrm{~cm}^{-1}$ can clearly be seen in Fig. 2 . In the Raman spectra measured with $532 \mathrm{~nm}$ and $633 \mathrm{~nm}$ laser excitations, the band at $647 \pm 3 \mathrm{~cm}^{-1}$ becomes the main signal for the samples having higher degrees of inversion (Fig. S5, ESI $\dagger$ ). This increase in intensity is accompanied by a shift of the position of the maximum from $647 \pm 3 \mathrm{~cm}^{-1}$ to $642 \pm 3 \mathrm{~cm}^{-1}$. 

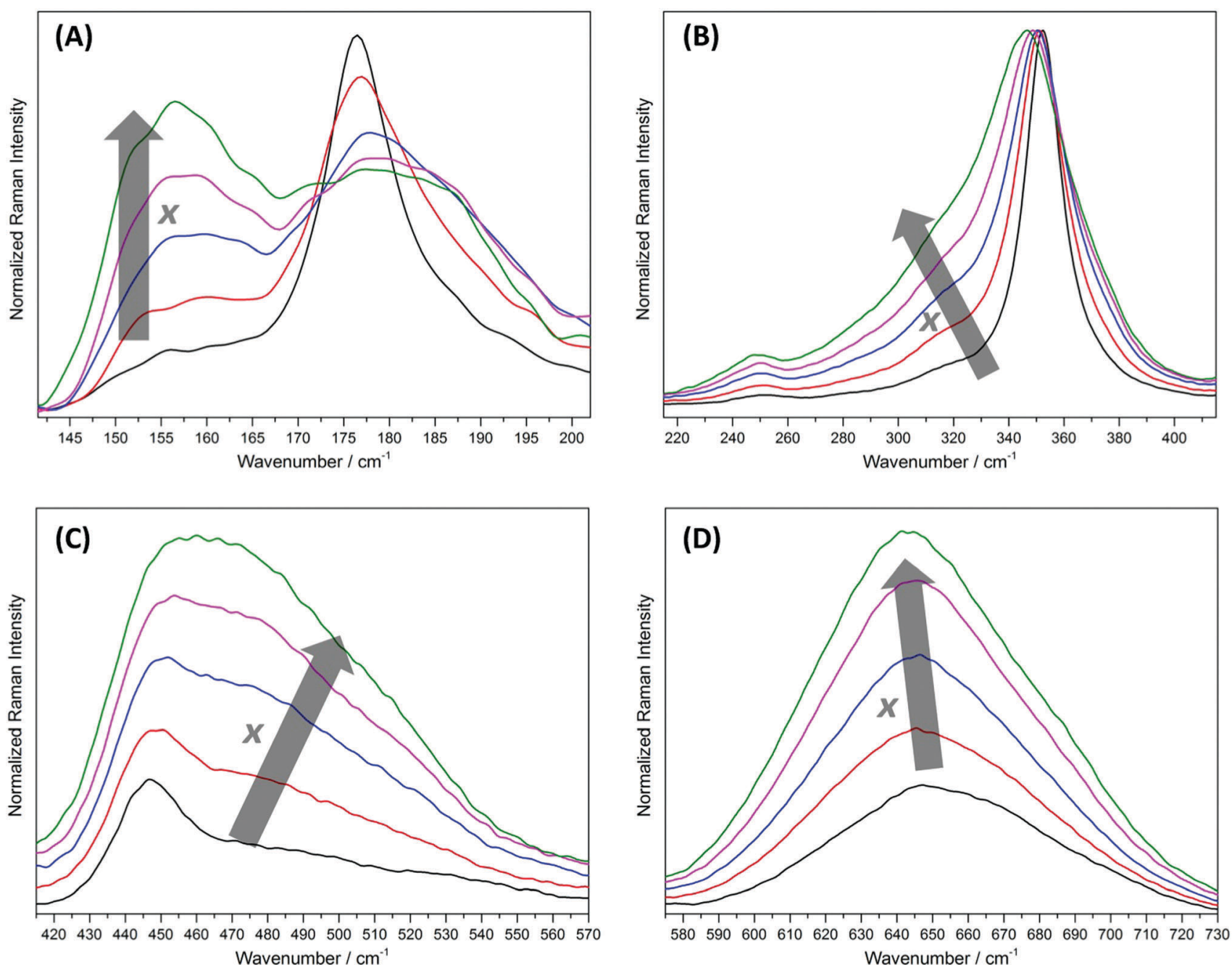

Fig. 3 Raman spectra (785 nm excitation source) from (A) $141.5 \mathrm{~cm}^{-1}$ to $202 \mathrm{~cm}^{-1}$, (B) $215 \mathrm{~cm}^{-1}$ to $415 \mathrm{~cm}^{-1}$, (C) $415 \mathrm{~cm}^{-1}$ to $570 \mathrm{~cm}^{-1}$, and (D) 575 $\mathrm{cm}^{-1}$ to $730 \mathrm{~cm}^{-1}$ of the ZFO samples with increasing degree of inversion ( - ZFO_773, $x=0.074 \pm 0.011 ;-Z F O \_873, x=0.104 \pm 0.013 ;-Z F O \_973$, $x=0.134 \pm 0.008 ;-$ ZFO_1073, $x=0.159 \pm 0.010 ;-$ ZFO_1173, $x=0.203 \pm 0.017)$.

It should be noticed that the ratio between two Raman scattering signals seems to depend on the degree of inversion. The intensity ratio between the Raman shifts at 352 and $647 \mathrm{~cm}^{-1}$ vs. the degree of inversion was fitted with an exponential decay function. The obtained results are shown in the supporting information (Fig. S8, ESI $\dagger$ ).

Fig. 4A shows the calculated Raman spectra of normal and inverse ZFO. The position and relative intensity of the calculated frequencies for a degree of inversion of $x=0$ show a reasonably good agreement with the experimental result obtained for $x \approx 0.073$. It is worth mentioning that the FWHM of the Raman signals cannot be calculated (therefore, an arbitrary value of $8 \mathrm{~cm}^{-1}$ was used to plot the results) and that vibrational wavenumbers from DFT calculations are typically larger than the observed experimentally. ${ }^{44}$ This is not only due to the harmonic approximation but also to the finite basis sets. ${ }^{44}$ Furthermore, the computation of vibrational wavenumbers was shown to be dependent on the method. ${ }^{44,45}$ Howard et al. considered vibrational wavenumbers within $20 \mathrm{~cm}^{-1}$ of the reference values as accurate. Thus, the calculated spectrum for $x=0$, with deviations of 15.5 to $48 \mathrm{~cm}^{-1}$ (5.7 to $8.8 \%$, respectively) from the experimental data obtained for a ZFO sample with $x \approx 0.073$, is reasonably good. Scaling factors are often applied to improve the agreement between the calculated and experimental results. ${ }^{44}$ Using scaling factors would also align the calculated spectrum presented in Fig. $4 \mathrm{~B}$ with the experimental spectrum obtained for ZFO with $x \approx 0.073$. However, this is not scientifically reasonable since the degree of inversion of the calculated ZFO $(x=0)$ and the synthesized ZFO $(x \approx 0.073)$ are not equal. Since the maximal inversion achieved experimentally is $x=0.203 \pm 0.017$, the calculated spectrum with an inversion of $x=1$ cannot be compared directly. Nevertheless, the trends observed experimentally upon increasing disorder may be related to the theoretical spectra.

In the region from $150 \mathrm{~cm}^{-1}$ to $250 \mathrm{~cm}^{-1}$ it can be seen a prominent signal shift to higher wavenumbers with increasing intensity as the inversion increases. In agreement with the experimental result, the Raman signal observed in this region 

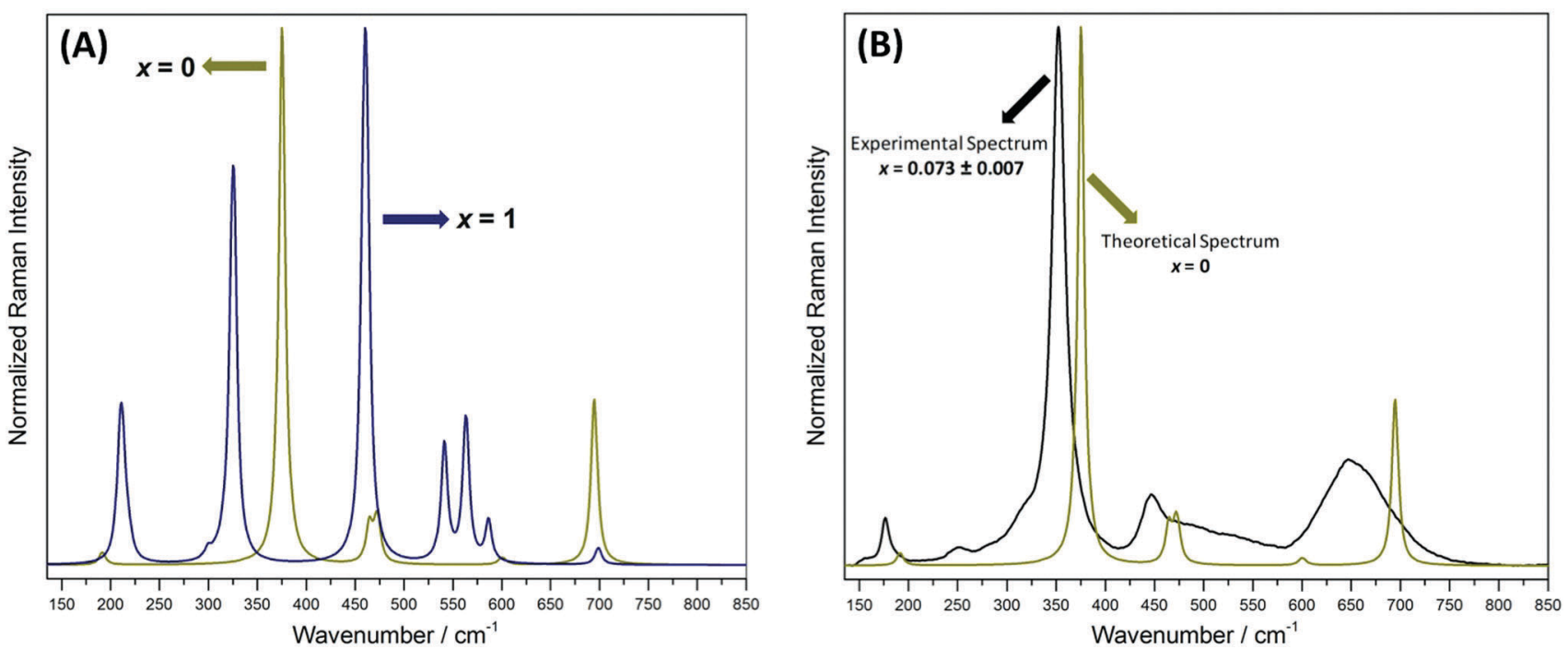

Fig. 4 (A) Calculated Raman spectra of ZFO with $x=0$ and $x=1$. (B) Comparison between the calculated Raman spectrum of ZFO with $x=0$ and the experimental Raman spectrum of ZFO with $x=0.074 \pm 0.011$.

for $x=0$ is shifted to higher wavenumbers in the calculated spectrum for $x=1$. Vibrational analysis confirms the assumption that this signal arises from wagging of the tetrahedral ion, explaining the shift to higher wavenumbers when $\mathrm{Zn}$ atoms are replaced by the lighter $\mathrm{Fe}$ atoms.

The Raman signal located at $375 \mathrm{~cm}^{-1}$ for the normal ZFO shifts to $325 \mathrm{~cm}^{-1}$ and exhibits a shoulder at $310 \mathrm{~cm}^{-1}$. This trend is once more in very good agreement with the experimental results. Vibrations of both, the octahedrally and tetrahedrally coordinated ions contribute to this signal.

The double peak obtained at $464 \mathrm{~cm}^{-1}$ and $472 \mathrm{~cm}^{-1}$ for $x=0$ shifts to slightly smaller wavenumbers $\left(459 \mathrm{~cm}^{-1}\right.$ and $462 \mathrm{~cm}^{-1}$ ) under inversion and increases in intensity, being the most pronounced signal for $x=1$. Although the vibrational analysis mainly ascribes these signals to the wagging of the tetrahedrally coordinated ions, as was supposed above, this behavior is not completely in line with the experimental results shown in Fig. 3C.

The calculated spectrum for $x=0$ shows a small signal at $600 \mathrm{~cm}^{-1}$, which splits into three signals at $541 \mathrm{~cm}^{-1}$, $563 \mathrm{~cm}^{-1}$, and $586 \mathrm{~cm}^{-1}$ for $x=1$. This effect cannot be observed in the experimental spectrum obtained with $785 \mathrm{~nm}$ laser excitation since those signals vanish between the rather broad bands located at higher and lower wavenumbers. Nevertheless, the spectra measured with $532 \mathrm{~nm}$ and $633 \mathrm{~nm}$ laser excitations (Fig. S5, ESI $\dagger$ ) show a weak signal at $573 \pm 3 \mathrm{~cm}^{-1}$, comparable with the calculated signal at $600 \mathrm{~cm}^{-1}$, for the sample with $x=0.074 \pm 0.011$. The intensity of this signal decreases as the degree of inversion increases. This decrease might be attributed to the split of this signal into three bands at lower wavenumbers, which contribute to the broadness of the band observed between $415 \mathrm{~cm}^{-1}$ and $560 \mathrm{~cm}^{-1}$.

The calculated signal at $695 \mathrm{~cm}^{-1}$ undergoes a slight shift to $699 \mathrm{~cm}^{-1}$ upon inversion, accompanied by a decreased intensity, which is contradictory to the experimental results (see Fig. 3D). This signal can mainly be ascribed to a symmetrical stretching of the $\mathrm{ZnO}_{4}$-tetrahedra in the normal $\mathrm{ZFO}$, and $\mathrm{FeO}_{4}$-tetrahedra in the inverse $\mathrm{ZFO}$.

As becomes clear from the above discussion, the degree of inversion has a great effect on the Raman scattering properties of ZFO. It is not surprising to find spectra in the literature showing different signal positions as well as diverse assignments. ${ }^{26,46}$ Furthermore, most authors presume a normal structure for the ZFO samples, thus not determining the degree of inversion. This assumption is not necessarily correct as the ordering of the sample can be easily modified by the temperature of preparation. Moreover, there are reports showing low-temperature synthesized ZFO nanoparticles with high degrees of inversion. ${ }^{18-20}$ Wang et al. ${ }^{26}$ presented a Raman spectrum of ZFO with $x=0.10$ together with an assignment of the bands. The signals at $221 \mathrm{~cm}^{-1}, 246 \mathrm{~cm}^{-1}, 355 \mathrm{~cm}^{-1}, 451 \mathrm{~cm}^{-1}$, and $647 \mathrm{~cm}^{-1}$ were identified as the five Raman active internal modes predicted by the group-theoretical analysis, having $\mathrm{F}_{2 \mathrm{~g}}, \mathrm{E}_{g}, \mathrm{~F}_{2 \mathrm{~g}}, \mathrm{~F}_{2 \mathrm{~g}}$, and $\mathrm{A}_{1 \mathrm{~g}}$ symmetry, respectively. The authors attributed the signals above $600 \mathrm{~cm}^{-1}$ to the motion of oxygen in the tetrahedral $\mathrm{AO}_{4}$ groups. The low-frequency modes were attributed to vibrations in the octahedral $\mathrm{BO}_{6}$ sites. The distinctive signals at $355 \mathrm{~cm}^{-1}, 451 \mathrm{~cm}^{-1}$, and $647 \mathrm{~cm}^{-1}$ agree with the results presented in this work but a discrepancy is found with the vibrations at $221 \mathrm{~cm}^{-1}$ and $246 \mathrm{~cm}^{-1}$. As was mentioned above, the weak band at $251 \pm 3 \mathrm{~cm}^{-1}$ arises from the disorder of the sample and is not one of the Raman active internal modes for the normal structure predicted by the group-theoretical analysis. The signal at $221 \mathrm{~cm}^{-1}$ was not observed in the present work neither for the $785 \mathrm{~nm}$ nor for the $532 \mathrm{~nm}$ and $633 \mathrm{~nm}$ laser excitations (Fig. S5, ESI †). A signal at $176.5 \mathrm{~cm}^{-1}$ appears in the result presented by Wang et al. but the resolution in this region, close to the acquisition limit of the spectrum, is poor. Finally, the internal mode reported in the present work at $573.5 \pm 3 \mathrm{~cm}^{-1}$ is not observed by Wang et al. because this signal becomes very weak while using a $785 \mathrm{~nm}$ laser excitation. The assignment 
Table 2 Assignment of the Raman active internal modes for normal ZFO proposed in the present work together with the assignment made by Wang et al. ${ }^{26}$

\begin{tabular}{llll}
\hline & \multicolumn{2}{l}{ Frequency/cm ${ }^{-1}$} & \\
\cline { 2 - 3 } & \multicolumn{2}{l}{ This work } & \\
\cline { 2 - 3 } Raman active internal mode & Theoretical & Experimental & Wang et al. \\
\hline $\mathrm{F}_{2 g}$ & 191 & $176.5 \pm 3$ & 221 \\
$\mathrm{E}_{g}$ & 375 & $352 \pm 3$ & 246 \\
$\mathrm{~F}_{2 g}$ & $464 / 472$ & $447 \pm 3$ & 355 \\
$\mathrm{~F}_{2 g}$ & 600 & $573 \pm 3$ & 451 \\
$\mathrm{~A}_{1 \mathrm{~g}}$ & 695 & $647 \pm 3$ & 647
\end{tabular}

of the Raman active internal modes proposed in this work and the assignment made by Wang et al. are presented in Table 2.

The UV-Vis-NIR diffuse reflectance spectra of the different ZFO samples are shown in Fig. 5. Three predominant absorption bands are observed in the regions from $220 \mathrm{~nm}$ to $670 \mathrm{~nm}$, $670 \mathrm{~nm}$ to $950 \mathrm{~nm}$, and $950 \mathrm{~nm}$ to $1600 \mathrm{~nm}$. The bands around $795 \mathrm{~nm}$ (ca. $1.56 \mathrm{eV}$ ) and $1200 \mathrm{~nm}$ (ca. $1.03 \mathrm{eV}$ ) present typical Gaussian shapes, whereas the band with a maximum around $425 \mathrm{~nm}$ saturates the detector and then decreases in intensity from $c a .400 \mathrm{~nm}$. The former band exhibits masked signals around $451 \mathrm{~nm}, 532 \mathrm{~nm}$, and $614 \mathrm{~nm}$. The determination and origin of these signals will be discussed below. Less reflectivity, namely more absorption, in the region between $500 \mathrm{~nm}$ and $700 \mathrm{~nm}$ is observed as the degree of inversion of the sample increases. This explains the darkening of the samples as $x$ changes from $0.074 \pm 0.011$ to $0.203 \pm 0.017$ (Fig. S9, ESI $\dagger$ ). The reflectivity of NIR radiation between $1400 \mathrm{~nm}$ and $2000 \mathrm{~nm}$ also decreases as the degree of inversion increases.

Three types of electronic transitions are found in $\mathrm{Fe}^{3+}$ rich oxides: ligand field transitions, transitions due to ligand-to-metal charge-transfer, and transitions resulting from simultaneous excitation of magnetically-coupled $\mathrm{Fe}^{3+}$ neighboring cations. ${ }^{47}$ The latter transitions are expected to be negligible for ZFO since there are no face-sharing $\mathrm{FeO}_{6}$ structures. The ligand field transitions for a $\mathrm{Fe}^{3+}$ ion occupying an octahedral site are due to the excitation of electrons from $t_{2 g}$ into $e_{g}$ orbitals. These orbitals are formed by the splitting of the $3 \mathrm{~d}$ orbitals due to the electrical field of the surrounding $\mathrm{O}^{2-}$ anions. Furthermore, both the $t_{2 g}$ and $e_{g}$ orbitals are also split because of the exchange energy (RussellSaunders coupling) and the resulting energetic states can be found in the respective Tanabe-Sugano diagram (Fig. S10, ESI $\dagger$ ). According to this diagram, a high spin $\mathrm{Fe}^{3+}$ ion exhibits a ${ }^{6} \mathrm{~A}_{1 \mathrm{~g}}$ ground state and the first three possible electronic transition are: ${ }^{6} \mathrm{~A}_{1 \mathrm{~g}}(\mathrm{G}) \rightarrow{ }^{4} \mathrm{~T}_{1 \mathrm{~g}}(\mathrm{G})\left[\left(\mathrm{t}_{2 \mathrm{~g}}^{\alpha}\right)^{3}\left(\mathrm{e}_{\mathrm{g}}^{\alpha}\right)^{2} \rightarrow\left(\mathrm{t}_{2 \mathrm{~g}}^{\alpha}\right)^{3}\left(\mathrm{e}_{\mathrm{g}}^{\alpha}\right)^{1}\left(\mathrm{t}_{2 \mathrm{~g}}^{\beta}\right)^{1}\right],{ }^{6} \mathrm{~A}_{1 \mathrm{~g}}(\mathrm{G}) \rightarrow$ ${ }^{4} \mathrm{~T}_{2 \mathrm{~g}}(\mathrm{G})\left[\left(\mathrm{t}_{2 \mathrm{~g}}^{\alpha}\right)^{3}\left(\mathrm{e}_{\mathrm{g}}^{\alpha}\right)^{2} \rightarrow\left(\mathrm{t}_{2 \mathrm{~g}}^{\alpha}\right)^{3}\left(\mathrm{e}_{\mathrm{g}}^{\alpha}\right)^{1}\left(\mathrm{t}_{2 \mathrm{~g}}^{\beta}\right)^{1}\right]$, and ${ }^{6} \mathrm{~A}_{1 \mathrm{~g}}(\mathrm{G}) \rightarrow{ }^{4} \mathrm{~A}_{1 \mathrm{~g}}(\mathrm{G})$ $\left[\left(\mathrm{t}_{2 \mathrm{~g}}^{\alpha}\right)^{3}\left(\mathrm{e}_{\mathrm{g}}^{\alpha}\right)^{2} \rightarrow\left(\mathrm{t}_{2 \mathrm{~g}}^{\alpha}\right)^{2}\left(\mathrm{t}_{2 \mathrm{~g}}^{\beta}\right)^{1}\left(\mathrm{e}_{\mathrm{g}}^{\alpha}\right)^{2}\right]$. Although all the transitions from the ground ${ }^{6} \mathrm{~A}_{1 \mathrm{~g}}$ state are spin and parity-forbidden, they become allowed due to the magnetic coupling of electronic spins of neighboring $\mathrm{Fe}^{3+}$ cations. $^{48-50}$

On the basis of the Tanabe-Sugano diagram, an assignment of the experimentally observed UV-Vis-NIR bands was done (Table 3). The signals at $1200 \mathrm{~nm}$ and $795 \mathrm{~nm}$ can be assigned to the ${ }^{6} \mathrm{~A}_{1 \mathrm{~g}} \rightarrow{ }^{4} \mathrm{~T}_{1 \mathrm{~g}}(\mathrm{G})$ and ${ }^{6} \mathrm{~A}_{1 \mathrm{~g}} \rightarrow{ }^{4} \mathrm{~T}_{2 \mathrm{~g}}(\mathrm{G})$ transitions, respectively. This corresponds with a value of $c a .14164 \mathrm{~cm}^{-1}(1.76 \mathrm{eV})$ for the energy of the octahedral crystal field, and $c a .624 \mathrm{~cm}^{-1}$ for the Racah parameter (Fig. S10, ESI $\dagger$ ). Additionally, the energy for the ${ }^{6} \mathrm{~A}_{1 \mathrm{~g}} \rightarrow{ }^{4} \mathrm{~A}_{1 \mathrm{~g}}(\mathrm{G})$ and ${ }^{6} \mathrm{~A}_{1 \mathrm{~g}} \rightarrow{ }^{4} \mathrm{~T}_{2 \mathrm{~g}}(\mathrm{D})$ transitions is estimated to be ca. $20248 \mathrm{~cm}^{-1}(494 \mathrm{~nm}, 2.51 \mathrm{eV})$ and $22300 \mathrm{~cm}^{-1}(448 \mathrm{~nm}, 2.76 \mathrm{eV})$, respectively. The latter value is in good agreement with the signal at $451 \mathrm{~nm}$ masked within the broad band from 220 to $670 \mathrm{~nm}$. Transitions from nonbonding molecular orbitals localized on the oxygen atoms

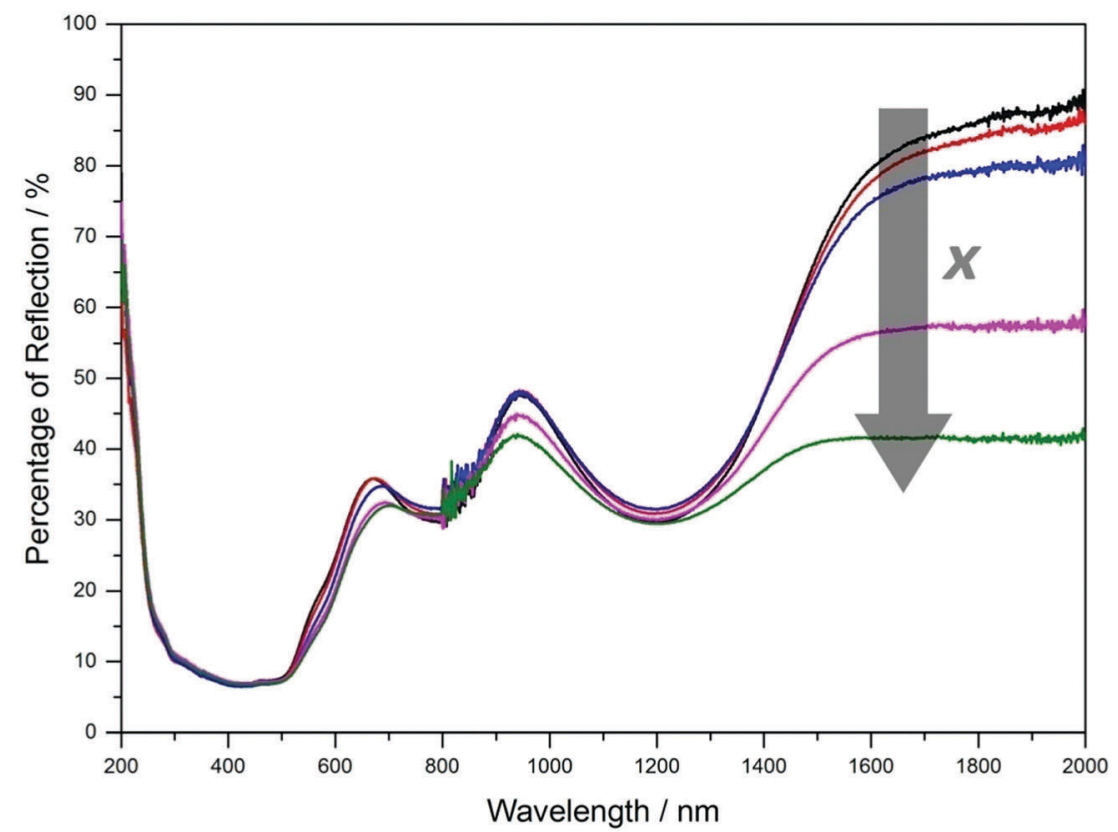

Fig. 5 UV-Vis-NIR diffuse reflectance spectra of the ZFO samples with increasing degree of inversion $(-$ ZFO_773, $x=0.074 \pm 0.011 ;-Z$ ZFO_873, $\left.x=0.104 \pm 0.013 ;-Z F O \_973, x=0.134 \pm 0.008 ;-Z F O \_1073, x=0.159 \pm 0.010 ;-Z F O \_1173, x=0.203 \pm 0.017\right)$. 
Table 3 Assignment of the experimentally observed electronic transitions of ZFO according to the ligand field theory considering Russell-Saunders coupling

\begin{tabular}{ll}
\hline Wavelength/nm & Transition \\
\hline 1200 & ${ }^{6} \mathrm{~A}_{1 \mathrm{~g}} \rightarrow{ }^{4} \mathrm{~T}_{1 \mathrm{~g}}(\mathrm{G})$ \\
795 & ${ }^{6} \mathrm{~A}_{1 \mathrm{~g}} \rightarrow{ }^{4} \mathrm{~T}_{2 g}(\mathrm{G})$ \\
614 & $\mathrm{O}^{2-}+\mathrm{Fe}^{3+} \rightarrow \mathrm{O}^{-}+\mathrm{Fe}^{2+}$ (indirect) \\
532 & $\mathrm{O}^{2-}+\mathrm{Fe}^{3+} \rightarrow \mathrm{O}^{-}+\mathrm{Fe}^{2+}$ (direct) \\
481 & ${ }^{6} \mathrm{~A}_{1 \mathrm{~g}} \rightarrow{ }^{4} \mathrm{~A}_{1 \mathrm{~g}}(\mathrm{G})$ \\
451 & ${ }^{6} \mathrm{~A}_{1 \mathrm{~g}} \rightarrow{ }^{4} \mathrm{~T}_{2 g}(\mathrm{D})$ \\
\hline
\end{tabular}

to the antibonding $t_{2 g} \mathrm{Fe}(3 \mathrm{~d})$ orbitals are reported in the literature for a vast variety of iron-based oxides. ${ }^{47,51}$ Because this electronic excitation is responsible for the optical band gap of the semiconducting ZFO, the derivation absorption spectrum fitting method (DASF) ${ }^{33}$ was applied to get more insight into the energy and the nature of the transition. Because the measured diffuse reflectance spectra do not correlate directly to the absorption spectra, the Kubelka-Munk radiative transfer model ${ }^{45}$ was first applied to determine the absorption coefficient. Rietveld refinement (Table 1) and SEM pictures (Fig. S11, ESI $\dagger$ ) reveal that the particles have similar size and shape. Thus, it was assumed that the different ZFO samples have the same scattering properties. The full mathematical deduction of the DASF model for diffuse reflectance data is presented in the supporting information. As can be seen from Fig. 6, three clear bands are observed at $2.02 \mathrm{eV}(614 \mathrm{~nm})$, $2.33 \mathrm{eV}(532 \mathrm{~nm})$, and $2.75 \mathrm{eV}(451 \mathrm{~nm})$, and a weak signal is observed at $2.58 \mathrm{eV}$ (481 nm). The bands at $2.58 \mathrm{eV}$ and $2.75 \mathrm{eV}$ can be assigned to the ${ }^{6} \mathrm{~A}_{1 \mathrm{~g}} \rightarrow{ }^{4} \mathrm{~A}_{1 \mathrm{~g}}(\mathrm{G})$ and ${ }^{6} \mathrm{~A}_{1 \mathrm{~g}} \rightarrow{ }^{4} \mathrm{~T}_{2 \mathrm{~g}}(\mathrm{D})$ transitions, respectively (Fig. S10, ESI $\dagger$ ). Consequently, the signal observed at
$2.02 \mathrm{eV}$ can be attributed to the $\mathrm{O}^{2-}+\mathrm{Fe}^{3+} \rightarrow \mathrm{O}^{-}+\mathrm{Fe}^{2+}$ transition. Moreover, the DASF analysis shows that this is an allowed and indirect transition (Fig. S12, ESI $\dagger$ ). Finally, the band at $2.33 \mathrm{eV}$ can be attributed to a direct $\mathrm{O}^{2-}+\mathrm{Fe}^{3+} \rightarrow \mathrm{O}^{-}+\mathrm{Fe}^{2+}$ transition. Table 3 lists the proposed assignment for the experimentally observed electronic transitions of ZFO.

Surprisingly, all the bands can be assigned considering only electronic transitions in the octahedrally coordinated $\mathrm{Fe}^{3+}$ ions. Similar results are known for other iron-based oxides having $\mathrm{Fe}^{3+}$ in both tetrahedral and octahedral positions. ${ }^{47}$ Pailhé $e t a l .{ }^{27}$ also assigned the UV-Vis-NIR absorption bands of a ZFO sample with $x=0.140$ to transitions involving $\mathrm{Fe}^{3+}$ in octahedral sites. Nevertheless, despite the authors deduced some of the transitions considering the orbital splitting due to the Russell-Saunders coupling, they mixed two different models by assigning transitions on the basis of a simple splitting of the $\mathrm{Fe}(3 \mathrm{~d})$ orbitals (into $t_{2 g}$ and $e_{g}$ orbitals) as well.

By comparing the spectra for the ZFO samples with different degrees of inversion, the presence of transitions involving tetrahedrally coordinated $\mathrm{Fe}^{3+}$ ions can be analyzed. The UVVis-NIR spectra from 0.90 to $6.0 \mathrm{eV}$ and the deconvolution of the three distinctive reflection bands employing Gaussian shaped curves are shown in Fig. 7. As the degree of inversion of the samples increases, the percentage of reflection at $c a .1 .5 \mathrm{eV}$ becomes higher (absorption decreases), and a broadening is observed for the band at $c a$. $1.0 \mathrm{eV}$ (absorption increases). The amount of $\mathrm{Fe}^{3+}$ ions in octahedrally coordinated sites has a considerable effect on the signal around $1.5 \mathrm{eV}$. As this value decreases, the absorption in this region becomes smaller. This effect is consistent with the assignment of this band to a transition involving $\mathrm{Fe}^{3+}$ ions in octahedral sites. On the

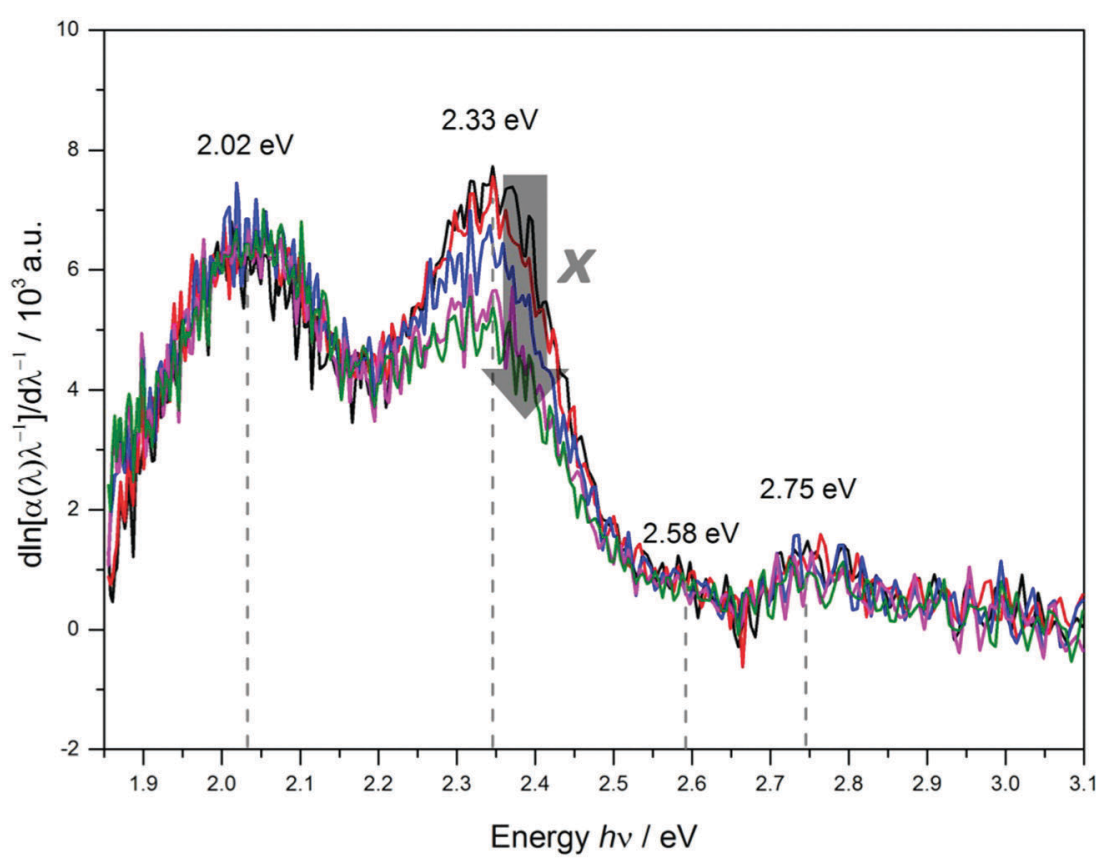

Fig. 6 Derivation of absorption spectrum fitting (DASF) method calculated from $670 \mathrm{~nm}$ to $400 \mathrm{~nm}$ for the ZFO samples with increasing degree of inversion (-ZFO_773, $x=0.074 \pm 0.011 ;-Z F O \_873, x=0.104 \pm 0.013 ;-Z F O \_973, x=0.134 \pm 0.008 ;-Z F O \_1073, x=0.159 \pm 0.010 ;-Z F O \_1173$, $x=0.203 \pm 0.017$ ). 

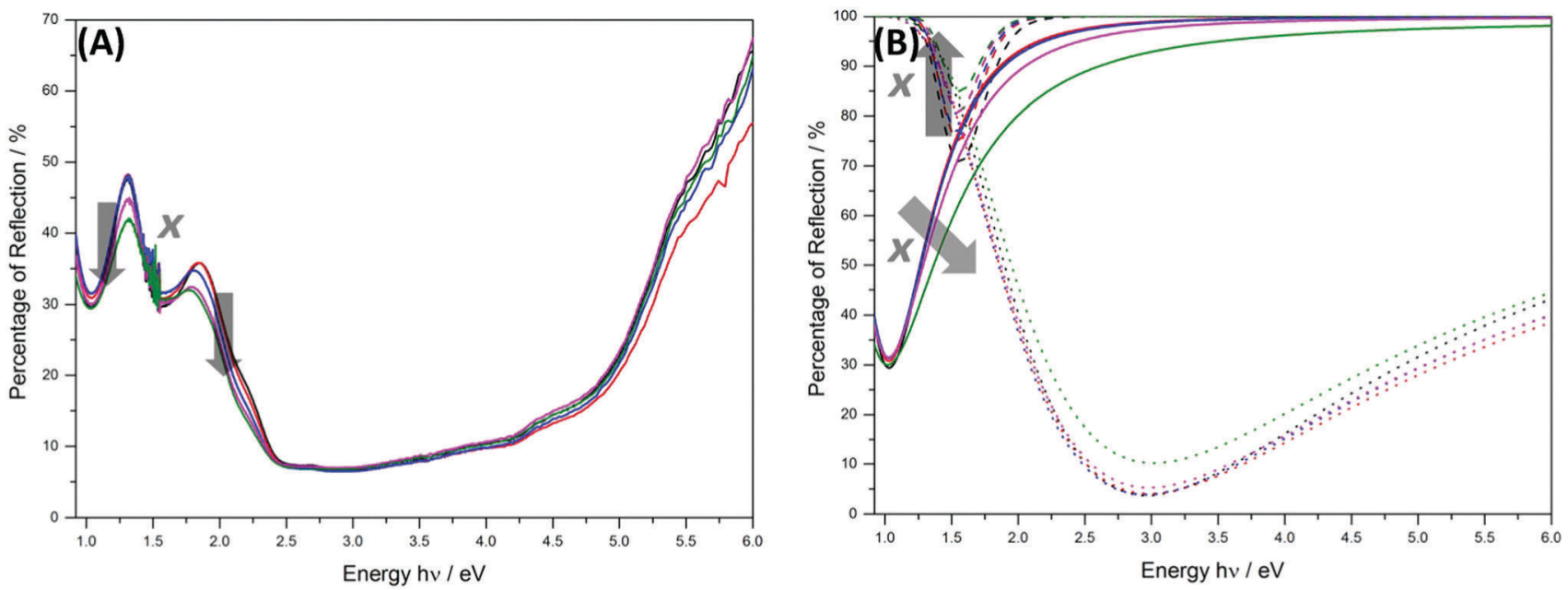

Fig. 7 (A) UV-VIS-NIR diffuse reflectance spectra from 0.9 to $6.0 \mathrm{eV}$ of the ZFO samples with increasing degree of inversion. (B) Deconvolution of the UV-VIS-NIR diffuse reflectance spectra employing Gaussian-shaped curves. The full line, dash line, and pointed line corresponds to the reflection bands at $1.03 \mathrm{eV}, 1.56 \mathrm{eV}$, and $3.00 \mathrm{eV}$, respectively. - ZFO_773, $x=0.074 \pm 0.011 ;-Z F O \_873, x=0.104 \pm 0.013 ;-Z F O \_973, x=0.134 \pm 0.008$; ZFO_1073, $x=0.159 \pm 0.010 ;-$ ZFO_1173, $x=0.203 \pm 0.017$.

other hand, an increasing amount of $\mathrm{Fe}^{3+}$ ions in tetrahedrally coordinated sites generates a higher absorption in the region around $1.0 \mathrm{eV}$. This signal cannot be attributed solely to transitions involving $\mathrm{Fe}^{3+}$ ions in tetrahedral sites because the intensity is already very high for the sample containing only $3.8 \%(x=0.074 \pm 0.011)$ of tetrahedrally coordinated $\mathrm{Fe}^{3+}$ ions and does not grow proportionally as the degree of inversion increases. Nevertheless, considering that the transitions originating from tetrahedrally coordinated $\mathrm{Fe}^{3+}$ ions might not be significantly different in energy than those arising from the octahedrally coordinated, ${ }^{51}$ an overlapping of both types of transitions can be expected at around $1.0 \mathrm{eV}$. Therefore, the broadening of the band in the NIR region close to $1.0 \mathrm{eV}$ can be explained by the contribution of the ligand field transitions due to $\mathrm{Fe}^{3+}$ ions occupying tetrahedral sites.

The imaginary part of the dielectric function, $\varepsilon_{2}$, which is directly related to the probability of photon absorption, ${ }^{52}$ was calculated in dependency on the excitation energy for ZFO with a degree of inversion of $x=0$ and $x=1$. The resulting spectra are given in Fig. 8.

Since the used theoretical approach is no multideterminantal ansatz, intra-atomic transitions cannot be described. The onset of

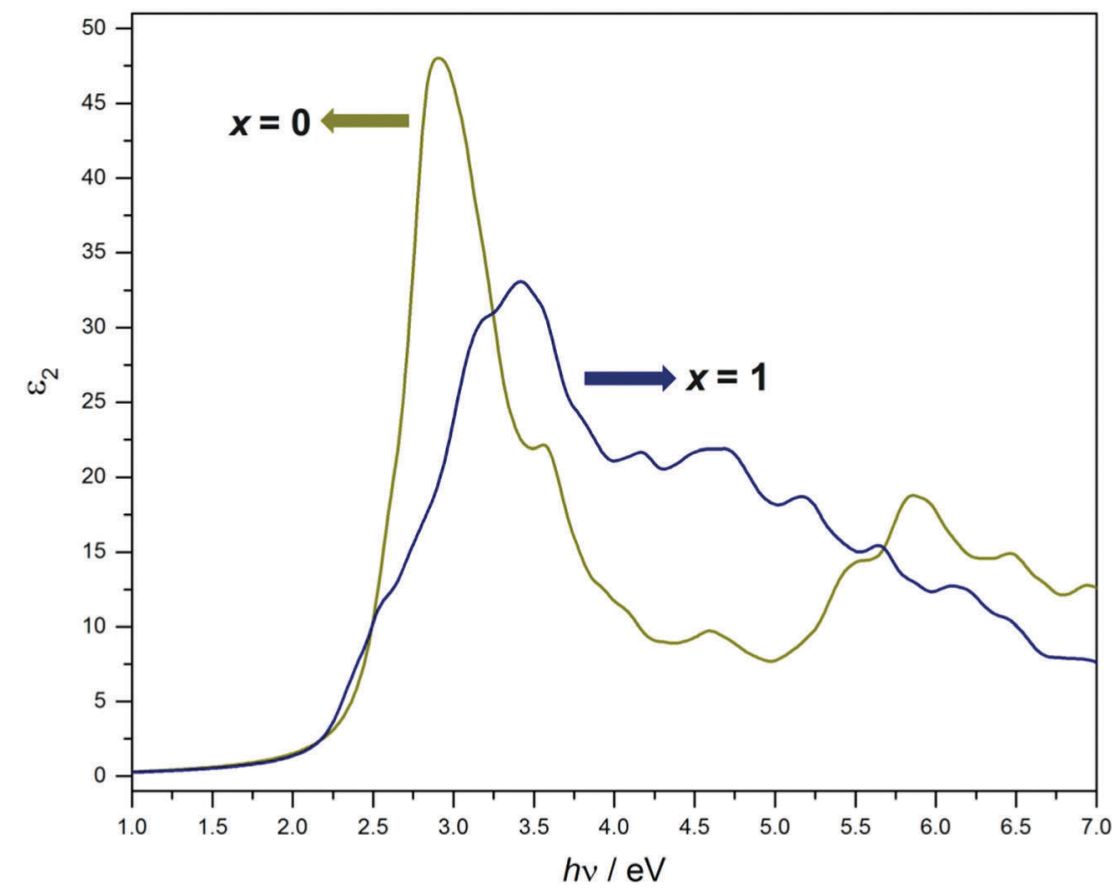

Fig. 8 Calculated imaginary part of the dielectric function $\varepsilon_{2}$ for optical spectrum of ZFO for ZFO with $x=0$ and $x=1$. 
the spectrum for the normal and the inverse ZFO is located at 2.3 and $2.1 \mathrm{eV}$, respectively. The position of the $\mathrm{O}^{2-}+\mathrm{Fe}^{3+} \rightarrow \mathrm{O}^{-}+\mathrm{Fe}^{2+}$ transition is in excellent agreement with the experimental result. Furthermore, both experiment and theory state that there is no difference in the band gap energy for different degrees of inversion. The theoretical spectrum in Fig. 8 shows that, upon inversion, the intensity of the band gap excitation decreases dramatically. A similar effect can be seen in Fig. 6 for the signal attributed to the direct band gap transition. As the degree of inversion increases, the area of the signal, and thus the absorption coefficient, decreases.

\section{Conclusions}

The effect of the degree of inversion on the Raman scattering and the UV-VIS-NIR reflectivity of spinel ZFO is elucidated. Based on the strong evidence collected, a new assignment for both, the Raman active internal modes and the electronic transitions is proposed for normal ZFO. As the degree of inversion increases, a larger contribution from the ligand field transitions of the tetrahedrally coordinated $\mathrm{Fe}^{3+}$ ions into the visible light absorptivity of the material is observed, producing a characteristic darkening of the sample. Conversely, no effect is observed on the energies of the transitions due to ligand-to-metal charge-transfer between $\mathrm{O}^{2-}$ and $\mathrm{Fe}^{3+}$ ions. Thereby, the band gap energy, with values of $2.02 \mathrm{eV}$ and $2.33 \mathrm{eV}$ for the indirect and direct transition, respectively, is found to be independent of the degree of inversion.

\section{Conflicts of interest}

There are no conflicts to declare.

\section{Acknowledgements}

The authors would like to thank the Laboratory of Nano- and Quantum-Engineering (LNQE) and Dr Dirk Dorfs and MSc Rasmus Himstedt for their support concerning the UV-VisNIR diffuse reflectance measurements. Financial support from the Deutsche Forschungsgemeinschaft in the large facility support INST144/435-1FUGG @ University of Bremen and under the program SPP 1613 (BA 1137/22-1) and the Niedersächsisches Ministerium für Wissenschaft und Kultur (NTHresearch group “ElektroBak”), is gratefully acknowledged.

\section{References}

1 R. Sharma, P. Thakur, P. Sharma and V. Sharma, Ferrimagnetic $\mathrm{Ni}^{2+}$ doped $\mathrm{Mg}-\mathrm{Zn}$ spinel ferrite nanoparticles for high density information storage, J. Alloys Compd., 2017, 704, 7-17.

2 M. P. Pileni, Magnetic fluids: Fabrication, magnetic properties, and organization of nanocrystals, Adv. Funct. Mater., 2001, 11, 323-336.

3 M. Pardavi-Horvath, Microwave applications of soft ferrites, J. Magn. Magn. Mater., 2000, 215, 171-183.
4 K. Yan, X. Wu, X. An and X. Xie, Facile synthesis and catalytic property of spinel ferrites by a template method, J. Alloys Compd., 2013, 552, 405-408.

5 A. B. Van Groenou, P. F. Bongers and A. L. Stuyts, Magnetism, microstructure and crystal chemistry of spinel ferrites, Mater. Sci. Eng., 1968, 3, 317-392.

6 D. H. Taffa, R. Dillert, A. C. Ulpe, K. C. L. Bauerfeind, T. Bredow, D. W. Bahnemann and M. Wark, Photoelectrochemical and theoretical investigations of spinel type ferrites $\left(\mathrm{M}_{\mathrm{x}} \mathrm{Fe}_{3-\mathrm{x}} \mathrm{O}_{4}\right)$ for water splitting: a mini-review, J. Photonics Energy, 2016, 7, 012009.

7 R. Dillert, D. H. Taffa, M. Wark, T. Bredow and D. W. Bahnemann, Research Update: Photoelectrochemical water splitting and photocatalytic hydrogen production using ferrites $\left(\mathrm{MFe}_{2} \mathrm{O}_{4}\right)$ under visible light irradiation, APL Mater., 2015, 3, 104001.

8 G. Song, F. Xin and X. Yin, Photocatalytic reduction of carbon dioxide over $\mathrm{ZnFe}_{2} \mathrm{O}_{4} / \mathrm{TiO}_{2}$ nanobelts heterostructure in cyclohexanol, J. Colloid Interface Sci., 2015, 442, 60-66.

9 S. Boumaza, A. Boudjemaa, A. Bouguelia, R. Bouarab and M. Trari, Visible light induced hydrogen evolution on new hetero-system $\mathrm{ZnFe}_{2} \mathrm{O}_{4} / \mathrm{SrTiO}_{3}$, Appl. Energy, 2010, 87, 2230-2236.

10 A. A. Tahir and K. G. U. Wijayantha, Photoelectrochemical water splitting at nanostructured $\mathrm{ZnFe}_{2} \mathrm{O}_{4}$ electrodes, J. Photochem. Photobiol., A, 2010, 216, 119-125.

11 J. H. Kim, J. H. Kim, J. W. Jang, J. Y. Kim, S. H. Choi, G. Magesh, J. Lee and J. S. Lee, Awakening solar watersplitting activity of $\mathrm{ZnFe}_{2} \mathrm{O}_{4}$ nanorods by hybrid microwave annealing, Adv. Energy Mater., 2015, 5, 1401933.

12 M. A. Valenzuela, P. Bosch, J. Jiménez-Becerrill, O. Quiroz and A. I. Páez, Preparation, characterization and photocatalytic activity of $\mathrm{ZnO}, \mathrm{Fe}_{2} \mathrm{O}_{3}$ and $\mathrm{ZnFe}_{2} \mathrm{O}_{4}$, J. Photochem. Photobiol., A, 2002, 148, 177-182.

13 E. Casbeer, V. K. Sharma and X. Z. Li, Synthesis and photocatalytic activity of ferrites under visible light: A review, Sep. Purif. Technol., 2012, 87, 1-14.

14 A. Arimi, L. Megatif, L. I. Granone, R. Dillert and D. W. Bahnemann, Visible-light photocatalytic activity of zinc ferrites, J. Photochem. Photobiol., A, 2018, DOI: 10.1016/ j.jphotochem.2018.03.014.

15 H. S. C. O'Neill, Temperature dependence of the cation distribution in zinc ferrite $\left(\mathrm{ZnFe}_{2} \mathrm{O}_{4}\right)$ from powder XRD structural refinements, Eur. J. Mineral., 1992, 4, 571-580.

16 A. Pavese, D. Levy and A. H. Hoser, Cation distribution in synthetic zinc ferrite $\left(\mathrm{Zn}_{0.97} \mathrm{Fe}_{2.02} \mathrm{O}_{4}\right)$ from in situ hightemperature neutron powder diffraction, Am. Mineral., 2000, 85, 1497-1502.

17 F. Bræstrup, B. C. Hauback and K. K. Hansen, Temperature dependence of the cation distribution in $\mathrm{ZnFe}_{2} \mathrm{O}_{4}$ measured with high temperature neutron diffraction, J. Solid State Chem., 2008, 181, 2364-2369.

18 M. J. Akhtar, M. Nadeem, S. Javaid and M. Atif, Cation distribution in nanocrystalline $\mathrm{ZnFe}_{2} \mathrm{O}_{4}$ investigated using x-ray absorption fine structure spectroscopy, J. Phys.: Condens. Matter, 2009, 21, 1-9. 
19 T. Kamiyama, K. Haneda, T. Sato, S. Ikeda and H. Asano, Cation distribution in $\mathrm{ZnFe}_{2} \mathrm{O}_{4}$ fine particles studied by neutron powder diffraction, Solid State Commun., 1992, 81, 563-566.

20 S. Nakashima, K. Fujita, K. Tanaka, K. Hirao, T. Yamamoto and I. Tanaka, First-principles XANES simulations of spinel zinc ferrite with a disordered cation distribution, Phys. Rev. B: Condens. Matter Mater. Phys., 2007, 75, 2-9.

21 J. Kurian and M. J. Mathew, Structural, optical and magnetic studies of $\mathrm{CuFe}_{2} \mathrm{O}_{4}, \mathrm{MgFe}_{2} \mathrm{O}_{4}$ and $\mathrm{ZnFe}_{2} \mathrm{O}_{4}$ nanoparticles prepared by hydrothermal/solvothermal method, J. Magn. Magn. Mater., 2018, 451, 121-130.

22 V. Šepelák, K. Tkáčová, V. V. Boldyrev, S. Wigmann and K. D. Becker, Mechanically induced cation redistribution in $\mathrm{ZnFe}_{2} \mathrm{O}_{4}$ and its thermal stability, Phys. B, 1997, 234-236, 617-619.

23 M. Mozaffari, M. Eghbali Arani and J. Amighian, The effect of cation distribution on magnetization of $\mathrm{ZnFe}_{2} \mathrm{O}_{4}$ nanoparticles, J. Magn. Magn. Mater., 2010, 322, 3240-3244.

24 Q. Yuan, L. Pan, R. Liu, J. Wang, Z. Liao, L. Qin, J. Bi, D. Gao and $\mathrm{J} . \mathrm{Wu}$, Cation distribution and magnetism in quenched $\mathrm{ZnFe}_{2} \mathrm{O}_{4}$, J. Electron. Mater., 2018, 47, 3608-3614.

25 V. G. Harris and V. Šepelák, Mechanochemically processed zinc ferrite nanoparticles: Evolution of structure and impact of induced cation inversion, J. Magn. Magn. Mater., 2018, 465, 603-610.

26 Z. Wang, D. Schiferl, Y. Zhao and H. S. C. O'Neill, High pressure Raman spectroscopy of spinel-type ferrite $\mathrm{ZnFe}_{2} \mathrm{O}_{4}$, J. Phys. Chem. Solids, 2003, 64, 2517-2523.

27 N. Pailhé, A. Wattiaux, M. Gaudon and A. Demourgues, Correlation between structural features and vis-NIR spectra of $\alpha-\mathrm{Fe}_{2} \mathrm{O}_{3}$ hematite and $\mathrm{AFe}_{2} \mathrm{O}_{4}$ spinel oxides $(\mathrm{A}=\mathrm{Mg}, \mathrm{Zn})$, J. Solid State Chem., 2008, 181, 1040-1047.

28 K. Lagarec and D. G. Rancourt, Recoil 1.05 Mössbauer Analysis software, Dep. Physics, Univ. Ottawa, Ottawa, ON, Canada, 2002.

29 R. Dovesi, R. Orlando, B. Civalleri, R. Roetti, V. R. Saunders and C. M. Zicovich-Wilson, CRYSTAL: a computational tool for the $a b$ initio study of the electronic properties of crystals, Z. Kristallogr. - Cryst. Mater., 2005, 220, 571-573.

30 A. V. Krukau, O. A. Vydrov, A. F. Izmaylov and G. E. Scuseria, Influence of the exchange screening parameter on the performance of screened hybrid functionals, J. Chem. Phys, 2006, 125, 224106.

31 P. J. Stephens, F. J. Devlin, C. F. Chabalowski and M. J. Frisch, $A b$ initio calculation of vibrational absorption and circular dichroism spectra using density functional force fields, J. Phys. Chem., 1994, 98, 11623-11627.

32 R. J. Hill, J. R. Craig and G. V. Gibbs, Systematics of the spinel structure type, Phys. Chem. Miner., 1979, 4, 317-339.

33 D. Souri and Z. E. Tahan, A new method for the determination of optical band gap and the nature of optical transitions in semiconductors, Appl. Phys. B: Lasers Opt., 2015, 119, 273-279.

34 G. Kresse and J. Furthmüller, Efficient iterative schemes for $a b$ initio total-energy calculations using a plane-wave basis set, Phys. Rev. B: Condens. Matter Mater. Phys., 1996, 54, 11169-11186.
35 L. Hedin, New method for calculating the oneparticleGreen's function with application to the electrongas-problem, Phys. Rev., 1965, 139, A796-A823.

36 M. Rohlfing and S. G. Louie, Electron-hole excitations and optical spectra from first principles, Phys. Rev. B: Condens. Matter Mater. Phys., 2000, 62, 4927-4944.

37 R. M. Cornell and U. Schwertmann, in The Iron Oxides: Structure, Properties, Reactions, Occurences and Uses, WILEYVCH, Darmstadt, 2nd edn, 2004, pp. 139-183.

38 H. B. Callen, S. E. Harrison and C. J. Kriessman, Cation distributions in ferrospinels. Theoretical, Phys. Rev., 1956, 103, 851-856.

39 A. Navrotsky and O. J. Kleppa, The thermodynamics of cation distributions in simple spinels, J. Inorg. Nucl. Chem., 1967, 29, 2701-2714.

40 H. S. C. O'Neill and A. Navrotsky, Simple spinels: crystallographic parameters, cation radii, lattice energies, and cation distribution, Am. Mineral., 1983, 68, 181-194.

41 H. S. C. O’Neill and A. Navrotsky, Cation distributions and thermodynamic properties of binary spinel solid solutions, Am. Mineral., 1984, 69, 733-753.

42 W. B. White and B. A. DeAngelis, Interpretation of the vibrational spectra of spinels, Spectrochim. Acta, Part A, 1967, 23A, 985-995.

43 P. R. Graves, C. Johnston and J. J. Campaniello, Raman scattering in spinel structure ferrites, Mater. Res. Bull., 1988, 23, 1651-1660.

44 A. P. Scott and L. Radom, Harmonic vibrational frequencies: An evaluation of Hartree-Fock, Møller-Plesset, quadratic configuration interaction, density functional theory, and semiempirical scale factors, J. Phys. Chem., 1996, 100, 16502-16513.

45 J. C. Howard, J. D. Enyard and G. S. Tschumper, Assessing the accuracy of some popular DFT methods for computing harmonic vibrational frequencies of water clusters, J. Chem. Phys., 2015, 143, 214103.

46 Z. Ž. Lazarević, D. L. Sekulić, V. N. Ivanovski and N. Ž. Romčević, A structural and magnetic investigation of the inversion degree in spinel $\mathrm{NiFe}_{2} \mathrm{O}_{4}, \mathrm{ZnFe}_{2} \mathrm{O}_{4}$ and $\mathrm{Ni}_{0.5} \mathrm{Zn}_{0.5-}$ $\mathrm{Fe}_{2} \mathrm{O}_{4}$ ferrites prepared by soft mechanochemical synthesis, Int. J. Chem. Mol. Nucl. Mater. Metall. Eng., 2015, 9, 1066-1070.

47 D. M. Sherman and T. D. Waite, Electronic spectra of $\mathrm{Fe}^{3+}$ oxides and oxide hydroxides in the near IR to near UV, Am. Mineral., 1985, 70, 1262-1269.

48 J. Ferguson, H. J. Guggenheim and Y. Tanabe, The effects of exchange interactions in the spectra of octahedral manganese. II. Compounds, J. Phys. Soc. Jpn., 1966, 21, 692-704.

49 J. J. Krebs and W. G. Maisch, Exchange effects in the opticalabsorption spectrum of $\mathrm{Fe}^{3+}$ in $\mathrm{Al}_{2} \mathrm{O}_{3}$, Phys. Rev. B: Condens. Matter Mater. Phys., 1971, 4, 757-769.

50 L. L. Lohr, Spin-forbidden electronic excitations in transition metal complexes, Coord. Chem. Rev., 1972, 8, 241-259.

51 D. M. Sherman, The electronic structures of $\mathrm{Fe}^{3+}$ coordination sites in iron oxides: Applications to spectra, bonding, and magnetism, Phys. Chem. Miner., 1985, 12, 161-175.

$52 \mathrm{P} . \mathrm{Yu}$ and M. Cardona, Fundamentals of Semiconductors, Springer, 4th edn, 2010. 